\title{
The financing strategy of agricultural supply chain based on cost sharing and buyer guarantee is considered in smart agriculture
}

\author{
LU Qi hui ${ }^{1}$,Tan Qian hong ${ }^{* 2}$ \\ ${ }^{1}$ School of Business Administration, Zhejiang Gongshang University Hang zhou, China \\ ${ }^{2}$ School of Business Administration, Zhejiang Gongshang University Hang zhou, China
}

\begin{abstract}
Supported by the agricultural technology, the intelligent agricultural development is flourishing. However, due to the high technology cost and investment risk, intelligent agriculture in China is still in the exploration stage. This article designs the appropriate cost sharing mechanism under the two-stage supply chain system, which composes of a farmer, a core enterprise and a commercial bank. With the comparison between commercial bank financing model and the buyer guarantees financing model, this paper researches the optimal decisions of supply chain members and the influence of the cost-sharing ratio, technical input gain effect and the buyer guarantees ratio. The results show that the profit will increase with the add of technical input gain effect. Besides, only under certain conditions, cost sharing is valuable to each member. Finally, numerical examples show existing an optimal interest rate spread area that all members would benefit from the buyer guarantee financing model.
\end{abstract}

\section{Introduction}

Modern agriculture is based on equipment and digitization, information technologies such as $5 \mathrm{G}$, artificial intelligence, data center, full scene + smart warehouse. The potential market size of smart agriculture in China is expected to grow from 13.7 billion in 2015 to 26.8 billion in 2020 . However, the smart agricultural technology tends to face such problems as high risk, long return cycle, small scale, scattered resources and characteristics of periodic. Besides, agricultural supply chain production in our country is instability which contributes to the low level of credit. In this case, the farmers face serious financing difficult problem, which limits the development of intelligent agriculture. In 2018, our country rural financial gap has more than 3 trillion yuan; In 2015, the scale of Internet finance for agriculture, rural areas and farmers in China was 12.5 billion yuan, and it will reach 320 billion yuan by 2020 , which has a broad space for development. However, it still cannot effectively meet the needs of smart agricultural development.

The emergence and application of the smart agriculture model of "company + farmer" and "intelligent manufacturing + service", to a certain extent, shares the pressure of agricultural material cost for farmers, promotes the improvement of agricultural production efficiency and realizes the improvement of agricultural product supply quality. Wen group, for example, adhere to the "company + peasant household" model of development, vigorously promote intelligent "fool" farming, aquaculture technology guidance to farmers, such as full-service, share the farmers technical input costs, reduce the management risk of the farmer, to promote the breeding industry evolution, greatly improve the efficiency and benefit of agricultural farming. In addition, the Zheng da cooperation with Jing dong Farm, Sinochem Agriculture and Alibaba, relying on agricultural technology and e-commerce dividends, effectively improve the efficiency and benefits of traditional agricultural production.

Moreover, a common method for the smart agriculture to solute the financing difficulties is that the core enterprises provide guarantee for the bank loans of farmers. For example, some guarantee companies established by New Hope Group are expected to provide 2.4 billion financing guarantee for farms. which distribute to alleviating the financing difficulties of upstream farmers and ensuring the stability of the supply chain. HSBC Rural Bank, Agricultural Bank of China and Pencil net have all ever carried out agricultural supply chain financing projects under the guarantee of core enterprises.

In addition to providing loan guarantees, core enterprises will also carry out all-round and in-depth cooperation with farmers through technology empowerment. For example, Delisi has signed agreements with farmers and guarantee companies to provide farmers with production materials such as feed, piglets, breeding technologies such as breeding management. The Bank of Qingdao provides financial support. When farmers cannot repay, the guarantee company can ask Delisi for loans.

Based on the above practical problems, this study also takes the agricultural random output factor into consideration, explores the value of technology input cost sharing under the background of smart agriculture, and analyzes the supply chain finance problems of buyer

* Corresponding author: 915312471@qq. Com 
guarantee. This paper puts forward the following considerations: Can technology input cost sharing reduce the risk of agricultural output uncertainty? Will technology cost sharing lead to profit outflow? What is the value of the buyer's financing guarantee?

At present, there are many researches on the optimization of enterprises in stochastic output. Cai Jian hu et al. (2017) ${ }^{[1]}$ studied the optimal pricing and input decision-making in stochastic output environment. The results show that the supplier's supply commitment can improve the supplier's revenue under certain conditions. On the basis of Cai Jian hu (2017), Li et al. (2017) ${ }^{[2]}$ further studied the effects of random demand, immediate purchase price and option price variation parameters on optimal business strategy and performance of supply chain. Jia nan Shen and Xiao feng Shao (2020) ${ }^{[3]}$ considered the problem of the optimal payment method in the capital constrained supply chain under production uncertainty and production capacity and analyzed the influence of production uncertainty and production capacity and other factors on the operation decision of supply chain. Wang Wen li and Guo Na (2020) ${ }^{[4]}$ considered the uncertainty of wholesale price of agricultural products, default of the company and other possible moral hazard of farmers, and studied the decision-making of the amount of agricultural inputs constrained by funds and the pricing strategy of the company.

There are literature studies on the coordination problem in the context of random output. Hu and Feng (2017) ${ }^{[5]}$ consider the service demand and revenue sharing mechanism in the case of output uncertainty, and point out that compared with the case of output uncertainty, suppliers can obtain higher revenue sharing or higher wholesale price when the output is uncertain. Cai et al. $(2017)^{[6]}$, Edward et al. (2019) ${ }^{[7]}$, Ye et al. (2020) ${ }^{[8]}$ and more studies have proved that reasonable repurchase or compensation contracts, revenue sharing, risk sharing and quantity discount can disperse random output risks and realize supply chain coordination.

In recent years, some studies began to consider the agricultural supply chain finance under the condition of random output. In the agricultural supply chain with random output, Huang Jian hui, Ye Fei et al. (2017) ${ }^{[9],}$ Huang Jian hui and Lin Qiang (2019) ${ }^{[10]}$ respectively explored the impact of government subsidies and commercial insurance on the optimal decision-making and interests of participants.

The research of this paper is related to the guarantee financing of enterprises in the supply chain. The existing literature is mainly divided into two categories: one is the guarantee influence research, which focuses on the influence of stochastic output on the decision-making and income of supply chain members. Yan et al. (2016) ${ }^{[11]}$ found that suppliers with high credit rating can maximize the overall profit of the supply chain by providing credit guarantee for bank loans. Boray et al. (2018) ${ }^{[12]}$ found that providing part or all of the bank financing guarantee can share the bank risk, and believed that a rational buyer guarantee should be positively correlated with the product profit margin and the reliability of suppliers.

Another kind of research focuses on the choice of supply chain financing mode and supply chain coordination, which is related to the study on the comparison of financing mode in this paper. By comparing the internal and external financing modes of bank financing and corporate financing, Zhu Lei et al. (2019) ${ }^{[13]}$ studied the optimal decision of members and the overall coordination of supply chain. Guo $\mathrm{Na}$ and Wang Wen li (2020) ${ }^{[14]}$ found that on the basis of the order price mechanism of "minimum guarantee acquisition and market change", companies always expect farmers to choose the financing method with low expected rate of return, while farmers with high self-owned funds prefer the financing method with high expected rate of return. Shi Li gang et al. (2020) ${ }^{[15]}$ explored the equilibrium decision of supply chain members under two peasant household financing modes of bank financing and discount of advance payment in agricultural supply chain. The results show that compared with bank financing, the discount financing model of advance payment cannot realize the Pareto improvement of supply chain members. Some scholars compared guaranteed financing with external financing. Jin et al. (2019) ${ }^{[16]}$ considered the financing strategy selection of bilateral supply chain with the coexistence of bank financing, bank trade credit and supplier guarantee under different conditions.

Research shows that a coordinated strategy of credit financing and secured financing does not necessarily reduce a bank's risk. Ding and Wan (2020) ${ }^{[17]}$ took the random situation at the output end into consideration and compared the decision problems of supply chain members when the manufacturer guarantees bank financing, the manufacturer advances and the two modes coexist, proving that the repayment and cost-sharing contract can coordinate the supply chain under the two financing modes of bank loans and the manufacturer advances.

The above literatures analyzed the agricultural random output problem and the agricultural supply chain secured financing problem from different perspectives, but seldom considered the cost sharing strategy of technical input under the smart agriculture, and seldom discussed the uncertain buyer guarantee financing model and financing balance problem on the supply side. Based on the intelligent agricultural supply chain with random output of agricultural products, this paper introduces the cost sharing mechanism of scientific and technological input, studies the financing mode of commercial banks and the guaranteed financing mode of core enterprises, and analyzes and solves the problem of farmers' capital constraints. This paper will analyze the optimal decision and income of supply chain members under the two financing modes, and explore the preference of supply chain members on the financing mode by comparing the financing modes. By means of numerical analysis, the influence of technology input and cost sharing ratio on agricultural supply chain financing performance is discussed.

\section{2 model description and hypothesis}

Considering a supply chain composed of core enterprises (hereinafter referred to as the buyer), farmers and commercial banks, farmers have the capacity $Q$ and initial 
capital $B$, and will further improve the output of agricultural products by introducing new production technologies. However, the initial capital may not meet the needs of production and operation, and farmers will face financing problems.

The decision-making sequence of supply chain members is divided into three periods. When $t=0$, the buyer provides the order contract to the upstream farmers and reaches a cost sharing agreement with them. The buyer decides whether to provide financing guarantee for farmers, and then decides the wholesale price $w$ of products. Farmers decide whether to accept the order according to the principle of maximizing their own interests, and then determine the level of technology investment $e$ in smart agriculture. When $\mathrm{t}=1$, the farmers are short of funds, they will apply to the bank for loans. At any moment, the farmers will hand over the agricultural products to the buyer, and the buyer will pay the farmers. The farmers will repay the principal and interest of the loan to the bank. If they cannot repay, the farmers will default. When the buyer guarantees, the farmers will bear limited liability after default. The buyer will repay the proportion $\gamma$ of the remaining loan principal and interest to the bank $(\gamma \in[0,1])$. When $\mathrm{t}=2$, the demand is realized, the buyer will sell the agricultural products to consumers according to the retail price $p$. This paper assumes that the unit production cost of farmers is $c$, the loan interest rate is $r_{i}$, and $i=(0,1)$, and the price of agricultural products is stable in the market, that means the sales price is determined. At the same time, the residual value and shortage loss of agricultural products are not considered.

Because agricultural production has the characteristics of random output, this paper uses $x$ to express the random output factor when there is no technology input, and uses $\mathrm{Q}(\mathrm{x}+\mathrm{g}(\mathrm{e}))$ to express the actual output after the smart agricultural science and technology input. In order to facilitate the analysis of the following supply chain model, it is assumed that the uniform distribution of the region is obeyed, and $\beta$ is the increase effect of technology input. $g(e)=\beta e$. It is also assumed that the cost of smart agricultural science and technology input is $\eta_{0} e^{2} / 2$, Where $\eta_{0}$ is the marginal coefficient of science and technology input, and $\eta_{0}=\eta c Q$. In order to ensure the stable production and operation of the supply chain of smart agriculture, the buyer is willing to bear part of the cost of science and technology input of smart agriculture, and the sharing ratio is $\theta$. In addition, the subscript 0 or 1 indicates the financing mode of commercial bank or buyer guaranteed financing respectively. $\Pi, \Omega, \Theta$ represent the profits of farmers, buyers and commercial banks respectively.

\section{Research on the BANK financing mode}

We use default point $x_{0}$ to represents the actual output rate when the loan can be repaid: $x_{0}=$ $\frac{\left(c Q\left(1+\bar{\theta} \eta e^{2} / 2\right)-B\right)\left(1+r_{0}\right)}{w Q}-g(e)$.
The form of farmers' profits will be related to the scope of the default point. If $0<x_{0}<1$, the farmers' expected profit function can be expressed as follows:

$$
\Pi_{0}=\int_{x_{0}}^{1} w Q(x+g(e))-w Q\left(x_{0}+g(e)\right) d x=\frac{w Q}{2}\left(1-x_{0}\right)^{2}
$$

If $x_{0}<0$, farmers cannot be default. The farmers' expected profit function can be expressed as follows:

$$
\begin{gathered}
\Pi_{0}=\int_{0}^{1} w Q(x+g(e)) d x-\left(1+r_{0}\right)\left(c Q\left(1+\frac{1}{2} \bar{\theta} \eta e^{2}\right)-B\right) \\
=\frac{w Q}{2}+w Q \beta e-\left(1+r_{0}\right)\left(c Q\left(1+\frac{1}{2} \bar{\theta} \eta e^{2}\right)-B\right)
\end{gathered}
$$

If $x_{0}>1$, farmers must default. Farmers will not participate in production, so this paper does not consider this situation.

The buyer's expected profit function is as follows:

$$
\begin{aligned}
& \Omega_{0}=\int_{0}^{1}(p-w)(x+g(e)) Q d x-\frac{1}{2} \theta \eta c Q e^{2} \\
& =\frac{1}{2} p Q-\frac{1}{2} w Q+p Q g(e)-w Q g(e)-\frac{1}{2} \theta \eta c Q e^{2}
\end{aligned}
$$

Proposition 1: In the financing model of commercial banks based on cost sharing, exists $\widetilde{\beta}_{0} \in\left(\bar{\beta}_{0}, \widehat{\beta}_{0}\right)$,when $\beta>\widetilde{\beta}_{0}$, the buyer's optimal wholesale price $w_{0}^{*}$ and the farmer's optimal technology input level $e_{0}^{*}$ are as follows:

$$
w_{0}^{*}=\left(p-\frac{(1+r) \bar{\theta} \eta c}{2 \beta^{2}}\right) \frac{1}{2+\frac{\theta}{\left(1+r_{0}\right) \bar{\theta}}} \cdot e_{0}^{*}=\frac{\beta w}{(1+r) \bar{\theta} \eta c}
$$

When $\tilde{\beta}_{0}<\beta<\hat{\beta}_{0}$, farmers will be the possibility of default; $\beta>\hat{\beta}_{0}$ farmers have no possibility of default. The point of default will decrease with the increase of $\beta$,then:

$$
\begin{gathered}
\bar{\beta}_{0}=\sqrt{\frac{\bar{\theta} \eta c\left(1+r_{0}\right)}{2 p}}, \hat{\beta}_{0}=\frac{T+\sqrt{T^{2}+8 p\left(1+r_{0}\right) \bar{\theta} \eta c}}{4 p} \\
T=\frac{2\left(2 \bar{\theta}\left(1+r_{0}\right)+\theta\right)}{\bar{\theta}} \cdot \sqrt{\frac{2 \bar{\theta} \eta c(c Q-B)}{Q}} .
\end{gathered}
$$

Proposition 1 shows that technology input can help farmers improve their actual output and reduce the possibility of default, which is beneficial to the supply chain. When the gain effect of technology input is very high, the possibility of default will not exist; when the gain effect of technology input is general, the effect and cost of technology input should be comprehensively measured to decide whether to invest and produce.

Proposition 2: According to the buyer's optimal wholesale price and the farmer's optimal level of technical input: we can obtain the following properties: when $\beta>$ $\hat{\beta}_{0},(1) e_{0}^{*}, w_{0}^{*}$ will decrease with $\eta$. (2) $e_{0}^{*}, w_{0}^{*}, \Pi_{0}^{*}$ will increase with $\beta$.

(1) shows that the optimal wholesale price and technology input level decided by supply chain members will decrease with the increase of technology input cost sensitivity coefficient. This is because the greater the cost sensitivity coefficient is, the more capital investment is needed, and the farmers will reduce the technology input level due to financial pressure.

(2) shows that the increase of technology input gain effect will promote the optimal wholesale price, 
technology input level and farmers' profit. Therefore, farmers should choose the technology with large gain effect for investment and application.

The profit function of a bank can be expressed as:

$$
\begin{aligned}
\theta_{0} & =\int_{x_{0}}^{1}\left(1+r_{0}\right)\left(c Q\left(1+\frac{1}{2} \bar{\theta} \eta e^{2}\right)-B\right) d x+\int_{0}^{x_{0}} w Q(x+g(e)) d x-\left(c Q\left(1+\frac{1}{2} \bar{\theta} \eta e^{2}\right)-B\right) \\
& =\left(1+r_{0}\right)\left(c Q\left(1+\frac{1}{2} \bar{\theta} \eta e^{2}\right)-B\right)\left(1-x_{0}\right)+\frac{w Q x_{0}^{2}}{2}+x_{0} w Q \beta e-\left(c Q\left(1+\frac{1}{2} \bar{\theta} \eta e^{2}\right)-B\right)
\end{aligned}
$$

If $x_{0} \leq 0$, if farmers did not default, the bank would be able to recover the principal and interest, profit of a bank can be expressed as:

$$
\begin{array}{r}
\Theta_{0}=\int_{x_{0}}^{1}\left(1+r_{0}\right)\left(c Q\left(1+\frac{1}{2} \bar{\theta} \eta e^{2}\right)-B\right) d x-(c Q(1+ \\
\left.\left.\frac{1}{2} \bar{\theta} \eta e^{2}\right)-B\right)=r_{0}\left(c Q\left(1+\frac{1}{2} \bar{\theta} \eta e^{2}\right)-B\right)
\end{array}
$$

Proposition 3: Under the bank financing mode, the buyer's cost sharing will have the following effects on the profits of supply chain members. (1) $e_{0}^{*}$ is a convex function about the cost sharing proportion $\theta$, and $w_{0}^{*}$ is a concave function about $\theta$. (2) $\Pi_{0}$ is a unimodal function of the cost sharing ratio $\theta$ of science and technology investment.

Proposition 3 (1) shows that when the buyer with sufficient capital bears more technology input costs, it can stimulate farmers to improve the level of agricultural production science and technology. When it is very large, the buyer will lower the wholesale price to ensure their own profits, so farmers will face greater risk of default.

Proposition 3 (2) shows that cost sharing can improve the level of technology input and increase production, but excessive cost sharing will make farmers unprofitable, because it is necessary to find an appropriate proportion of cost sharing to achieve Pareto optimization.

\section{Research on the buyer's guarantee FINANCING MODE}

Similarly, under buyer's guarantee financing model, the default point $x_{1}=\frac{\left(c Q\left(1+\frac{1}{2} \theta \eta e^{2}\right)-B\right)\left(1+r_{1}\right)}{w Q}-g(e)$.

If $0<x_{1}<1$, the farmers' expected profit function can be expressed as follows:

$$
\Pi_{1}=\int_{x_{1}}^{1} w Q(x+g(e))-w Q\left(x_{1}+g(e)\right) d x=\frac{w Q}{2}\left(1-x_{1}\right)^{2}
$$

If $x_{1} \leq 0$, farmers cannot be default. The farmers' expected profit function can be expressed as follows:

$$
\begin{array}{r}
\Pi_{1}=\int_{0}^{1} w Q(x+g(e)) d x-\left(1+r_{1}\right)\left(c Q\left(1+\frac{1}{2} \bar{\theta} \eta e^{2}\right)-B\right) \\
=\frac{w Q}{2}+w Q \beta e-\left(1+r_{1}\right)\left(c Q\left(1+\frac{1}{2} \bar{\theta} \eta e^{2}\right)-B\right)
\end{array}
$$

If $x_{1}>1$, farmers must default. The farmer's optimal technology input level are as follows: $e_{1}^{*}=\frac{\beta w}{\left(1+r_{1}\right) \bar{\theta} \eta c}$.

If $0<x_{1}<1$, the buyer's expected profit function is as follows:

$$
\begin{gathered}
\Omega_{1}=\int_{0}^{1}(p-w)(x+g(e)) Q d x-\frac{1}{2} \theta \eta c Q e^{2}-\gamma \int_{0}^{x_{1}} w Q\left(x_{1}+g(e)\right)-w Q(x+g(e)) d x \\
=\frac{1}{2} p Q-\frac{1}{2} w Q+p Q g(e)-w Q g(e)-\frac{1}{2} \theta \eta c Q e^{2}-\gamma \frac{w Q x_{1}^{2}}{2}
\end{gathered}
$$

If $x_{1} \leq 0$, the buyer's expected profit function is as follows:

$$
\Omega_{1}=\frac{1}{2} p Q-\frac{1}{2} w Q+p Q g(e)-w Q g(e)-\frac{1}{2} \theta \eta c Q e^{2}
$$

Proposition 4: In the buyer guaranteed financing mode, the optimal wholesale price satisfies the following equation:

$$
\begin{gathered}
-\frac{Q}{2}+p Q \beta A-2 Q \beta A w-\theta \eta c Q A^{2} w+\frac{\gamma\left(1+r_{1}\right)^{2}(c Q-B)^{2}}{2 w^{2} Q} \\
+\frac{\gamma(c Q-B) \beta^{2}}{2 \bar{\theta} \eta c}-\frac{3}{8} \gamma \beta^{2} Q A^{2} w^{2}=0 \\
\text { and } A=\frac{\beta}{\left(1+r_{1}\right) \bar{\theta} \eta c}
\end{gathered}
$$

In the buyer guaranteed financing model, there is indeed an optimal wholesale price $w_{1}^{*}$, but it is difficult to find an analytical expression. Therefore, the following paper discusses the decision-making and income of supply chain members through numerical analysis.

If $0<x_{1}<1$, the expected profit function of banks is as follows:

$$
\begin{gathered}
\theta_{1}=\int_{x_{1}}^{1}\left(1+r_{1}\right)\left(c Q\left(1+\frac{1}{2} \bar{\theta} \eta e^{2}\right)-B\right) d x+\int_{0}^{x_{1}} w Q(x+g(e)) d x \\
+\gamma \int_{0}^{x_{1}}\left(\left(1+r_{1}\right)\left(c Q\left(1+\frac{1}{2} \bar{\theta} \eta e^{2}\right)-B\right)-w Q(x+g(e))\right) d x-\left(c Q\left(1+\frac{1}{2} \bar{\theta} \eta e^{2}\right)-B\right) \\
=\left(1+r_{1}\right)\left(c Q\left(1+\frac{1}{2} \bar{\theta} \eta e^{2}\right)-B\right)\left(1-x_{1}\right)+(1-\gamma)\left(\frac{w Q x_{1}^{2}}{2}+x_{1} w Q \beta e\right) \\
+\gamma\left(1+r_{1}\right)\left(c Q\left(1+\frac{1}{2} \bar{\theta} \eta e^{2}\right)-B\right) x_{1}-\left(c Q\left(1+\frac{1}{2} \bar{\theta} \eta e^{2}\right)-B\right)
\end{gathered}
$$

If $x_{1} \leq 0$, banks' profit is as follows:

$$
\Theta_{1}=r_{1}\left(c Q\left(1+\frac{1}{2} \bar{\theta} \eta e^{2}\right)-B\right)
$$

\section{Numerical analysis}

\subsection{The impact of technology input and cost sharing on the benefits of supply chain members in bank financing mode}

We use numerical analysis to studied the influence of technology input and cost sharing on supply chain in bank financing mode. The basic parameters are set as follows: $r_{0}=0.05, \eta=0.5, Q=200, p=200, c=50, B=1500$, $r l=0.05 \gamma=0.8$.

Figure 1 shows that when the gain effect of technology input is small, farmers and banks can benefit from the buyer's higher proportion of technology cost sharing. Therefore, when the level of technology input is low, farmers' acceptance of the buyer's cost sharing will be conducive to their own interests. Moreover, banks and farmers' strategic choices are closely related.

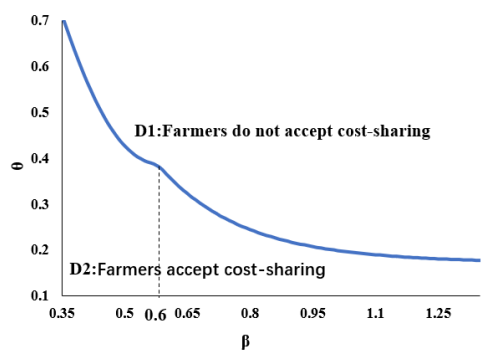

(a) 




(b)

Figure 1. The value of cost sharing ratio and technology input gain effect to farmers and banks

Figure 2 shows that when the technical input cost is high, the buyer's profit will always increase, because the income brought by the technical input is greater than the technical input cost borne. For farmers, there is an appropriate cost-sharing ratio to maximize their benefits. It can be concluded that the core enterprise can increase the profit of all members of the supply chain by helping vulnerable farmers share the cost.

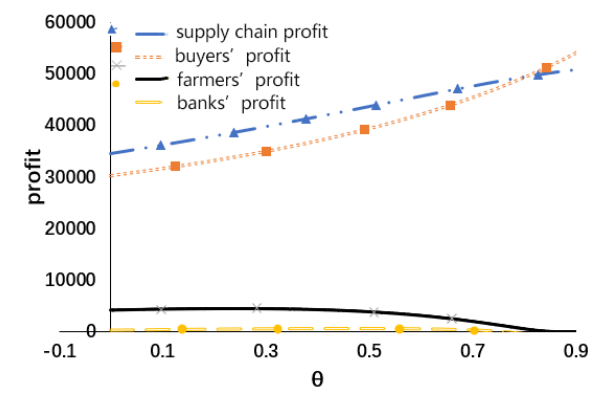

Figure 2. Relationship between cost-sharing ratio and profit of each member of supply chain

5.2 The impact of technology input and cost sharing on the benefits of supply chain members in buyers' guarantee financing mode

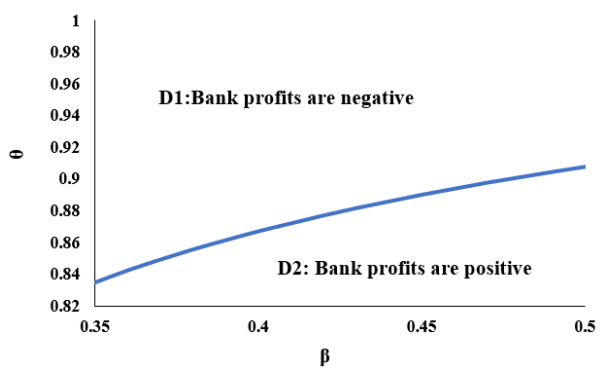

Figure 3. The relationship between cost sharing ratio, technology input gain effect and bank profit

Through comparison, it is found that buyer guarantee can expand the profitable area of banks, which indicates that the financing mode of core enterprise guarantee can have a positive effect on the interests of commercial banks and reduce the risks of commercial banks.

\section{Research on Financing Strategy of agricultural supply chain members}

\subsection{Comparison of optimal decisions among supply chain members}

proposition5: when $\beta<\widehat{\beta}_{0}, w_{1}^{*}>w_{0}^{*}, e_{1}^{*}>e_{0}^{*}$;or $w_{1}^{*}=w_{0}^{*}$, $e_{1}^{*}=e_{0}^{*}$.

This proposition shows that in the buyer-guaranteed financing model, the buyer will offer a higher wholesale price. This is because if the farmer goes bankrupt, the buyer will bear additional losses due to the guarantee liability, so the buyer will offer a higher wholesale price to reduce the risk of the farmer defaulting. The optimal level of technology input under buyer guarantee financing is always higher than that of the bank financing, which indicates that the guarantee financing of the buyer will increase the level of technology input of agricultural products. In general, the financing model of buyer guarantee is beneficial to farmers, and the buyer will bear the risk of guarantee to improve the profit of supply chain.

Figure 4(a) below shows that there is an appropriate cost-sharing ratio to enable farmers to obtain the maximum benefits. Figure 4(b) shows that for the buyer, when bank interest rates are the same, (1) cost-sharing mechanisms can always improve the buyer's profit in either bank financing or buyer guaranteed financing; (2) No matter how much the cost-sharing ratio is, the profit under bank financing is always greater than the profit under buyer guarantee. Figure 4(c) shows that buyer guarantee financing is conducive to the improvement of farmers' profits, while the buyer will lose a small part of profits. Besides, an appropriate cost-sharing ratio is conducive to the long-term development of the supply chain.

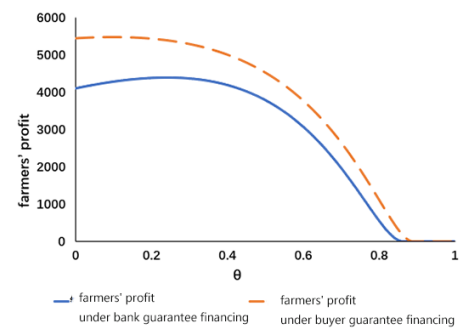

(a)

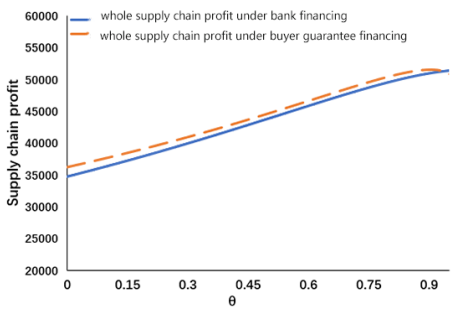

(b) 


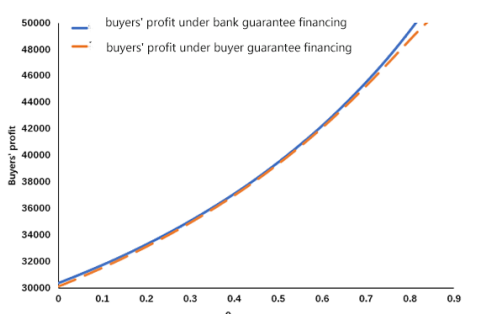

(c)

Figure 4. Cost sharing ratio impact on profits throughout the supply chain

\subsection{Financing strategy selection based on different bank interest rates}

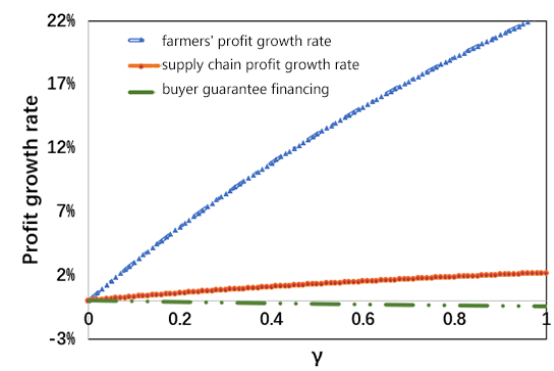

Figure 5. Influence of guarantee ratio on profit growth rate

It can be seen from figure 5 that the buyer guarantee financing mode is always beneficial to farmers. The buyer's guarantee ratio makes profit always less than that under the bank financing model. The total profit of the supply chain in the buyer secured financing model is always greater than that in the unsecured bank financing model. This shows that buy-side guaranteed financing does benefit the development of the supply chain.

\subsection{Financing strategy selection based on different bank interest rates}

The following is an analysis of the impact of the decline in interest rates on the financing mode preferences of all parties. Let's say that $\Delta r=r 0-r 1$ represents the reduction in the interest rate of buyer guaranteed financing. Figure 6 shows that when $\Delta \mathrm{r}$ and $\gamma$ are smaller, banks prefer buyer guarantee financing. There are three combinations of interest rate difference and guarantee ratio. Only in region $\mathrm{D} 2$, the financing preferences of buyers and banks are the same, while in regions D1 and D3, the financing preferences of buyers and banks are different.

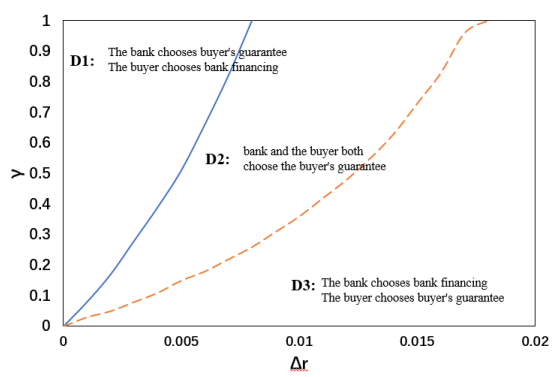

Figure 6. Optimal financing strategy when interest rate difference exists

\section{Conclusion and significance}

This paper mainly explores the smart agricultural supply chain including the farmers, core enterprises and commercial banks who are short of funds. Analyzes the decision-making of all parties under the financing mode of commercial banks and the buyer guarantee financing mode, then studying the problem of financing mode selection.

The study found that in the commercial bank financing model based on cost sharing, the profits of the supply chain members will increase with the add of the technical input gain effect. When technology gain effect is higher than the threshold, the farmer's default point will reduce gradually until it disappeared, and all supply chain members can get higher profits. However, the increase in the cost sharing ratio will only increase the buyer's profit; For farmers and banks, there is an exact cost sharing ratio to maximize their profits, which indicates that the buyer, as the leading enterprise, needs to consider the proper cost sharing rate and provide an appropriate cost sharing ratio for the stable development of the supply chain.

In addition, as for the buyer guarantee financing, the greater the proportion of buyer guarantee, the more favorable for farmers and banks; As for the leading buyer, it will lead to the loss of its own profit because it shares part of the operating risk. Finally, when the two financing modes coexist, the wholesale price and technical input level of buyer guarantee financing mode are higher than that under commercial bank financing mode, and the default point of farmers in buyer guarantee financing mode is lower. When banks are willing to lower interest rates, there is a combination of interest rate spreads and collateral ratios that allow all members of the supply chain to benefit from the buyer-guaranteed financing model.

\section{Acknowledgment}

I would like to first express my heartfelt thanks and sincerest respect to my tutor, Mr. Lu. Mr. Lu's persevering spirit of scientific research and his magnanimous and modest manner have always inspired me to keep learning knowledge and pursuing the realm of life. Needless to say, there are too many people who have helped me, I sincerely thank all the people who care and help me, thank them for giving me confidence, encourage me to persist, and constantly break through themselves, thank you.

National Natural Science Foundation of China (71672179)

\section{References}

1. Cai Jianhu, Jiang Feiying, Xue Tingting, Huang Weilai. (2017) A Pricing and Input Decision Model Considering Supply Commitment under Output Uncertainty [J]. Control and Decision, 32 (9): 16641671.

2. Li J C, Zhou Y W, Huang W Y.(2017) Production and procurement strategies for seasonal product supply chain under yield uncertainty with commitment - 
option contracts[J]. International Journal of Production Economics, 183: 208-222.

3. Shen Jiannan, Shao Xiaofeng. (2020) Operation Decision of Capital Constraining Supply Chain under Production Uncertainty [J].

Journal of Management Engineering, 34 (1) : 210 222.

4. Wang Wenli, Guo Na.(2020) Strategy of Ordering Agricultural Supply Chain Financing Considering Moral Hazard [J]. Journal of System Management, 29(2): 128-138.

5. $\mathrm{Hu} \mathrm{B}$ Y, Feng Y.Optimization and coordination of supply chain with revenue sharing contracts and service requirement under supply and demand uncertainty[J].Int.J.Production Economics,2017,183: 183-193.

6. Cai J H, Zhong M, Shang J, Huang W L.(2017) Coordinating VMI supply chain under yield uncertainty: Option contract, subsidy contract, and replenishment tactic $[\mathrm{J}]$. International Journal of Production Economics ,185: 196-210.

7. Edward A, Monjardino M.(2019) Contract design in agriculture supply chains with random yield $[\mathrm{J}]$.European Journal of Operational Research, 277(3): 1072-1082.

8. Ye F, Lin Q, Li Y N.(2020) Coordination for contract farming supply chain with stochastic yield and demand under CVaR criterion[J].Operational Research, 20(1) : 369-397.

9. Huang Jianhui, Ye Fei, Lin Qiang. Journal of Management Science,2017,2 (14) : 277-285.

10. Huang Jianhui, Lin Qiang.(2019) Government subsidy mechanism in agricultural supply chain financing with guarantee insurance and output uncertainty [J]. Chinese Management Science, 3 (27): 53-65.

11. Yan N, Sun B, Zhang H, Liu C. (2016) A partial credit guarantee contract in a capital-constrained supply chain: Financing equilibrium and coordinating strategy $[\mathrm{J}]$. International Journal of Production Economics, 173: 122-133.

12. Boray H, Andy W, Chiang D. (2018) Supporting small suppliers through buyer-backed purchase order financing $[\mathrm{J}]$.International Journal of Production Research, 56(18) : 1-24.

13. Zhu Lei, Wang Guohong, (2019) Wang Cong. Operation Decision of "Company + Farmer" Order Agricultural Supply Chain under Different Financing Modes [J].Industrial Engineering and Management, 24(05): $16-21+31$.

14. Guo Na, Wang Wenli.(2020) The purchase price is uncertain and the order is placed: the choice of financing mode of agricultural supply chain: external financing VS internal financing [J].Operations research and management 29(12): 188$196+230$

15. Shi Ligang, Peng Hongjun, (2020) Cong Jing. Research on Internal and External Financing Strategy of Order Agricultural Supply Chain under Capital Constraint $[\mathrm{J}]$.Operations Research and Management, 29(04): 62-69.

16. Jin W,Zhang Q H , Luo J w. (2019) Non-collaborative and collaborative financing in a bilateral supply chain with capital constraints[J].Omega, 88 .

17. Wen D, Wan G H. (2020) Financing and coordinating the supply chain with a capital-constrained supplier under yield uncertainty, International Journal of Production Economics, 230:1-12. 